The hand of god or the hand of Maradona? Believing in free will increases perceived intentionality of others' behavior

\author{
Oliver Genschow \\ (University of Cologne) \\ Davide Rigoni \\ (Ghent University) \\ Marcel Brass \\ (Ghent University)
}

\begin{abstract}
Author Note
Correspondence concerning this article should be addressed to Oliver Genschow, University of Cologne, Social Cognition Center Cologne, Richard-Strauss Str. 2, 50931 Cologne, Germany, E-Mail: oliver.genschow@uni-koeln.de This research was partially funded by a grant from the John Templeton Foundation's Philosophy and Science of Self-Control Project (15462).
\end{abstract}




\begin{abstract}
The question of whether free will actually exists has been debated in philosophy for centuries. However, how belief in free will shapes the perception of our social environment still remains open. Here we investigate whether belief in free will affects how much intentionality we attribute to other people. Study $1 \mathrm{a}$ and $1 \mathrm{~b}$ demonstrate a weak positive relation between the strength of belief in free will and the perceived intentionality of soccer players committing handball. This pattern even holds for behavior that is objectively not intentional (i.e., when the player touches the ball accidentally). Going one step further, in Study 2 we find a weak correlation between belief in free will and perceiving intentions in very abstract geometrical shapes. These findings suggest that whether individuals believe in free will or not changes the way they interpret others' behavior, which may have important societal consequences.
\end{abstract}

Keywords: Belief in free will; interpersonal perception; intention attribution 
That goal was scored a little bit by the hand of God and another bit by Maradona's head. (Diego Armando Maradona)

Thanks to Diego Armando Maradona, Argentina’s World Cup quarter-final against England in 1986 became one of the most famous games in soccer history. In the 51st minute, Maradona entered the penalty area, rose and punched the ball with his hand past England's onrushing goalkeeper. None of the officials spotted this misbehavior, letting Argentina finish the match with a victory. Confronted with TV replays clearly establishing that he had scored the goal with his hand, Maradona defended his behavior by claiming that it had not been himself but the hand of god that had scored the goal, indicating that he did not have intentional control over his own behavior. So, did Maradona actually commit handball intentionally or did he not? In the present article, we argue that the answer to this question depends on how much people believe in free will. More specifically, we argue that the more individuals believe in free will, the more they attribute intentionality to the behavior of others.

Free will is a cornerstone of our society and most people believe that they have free will (Baumeister, Masicampo, \& DeWall, 2009; Nahmias, Morris, Nadelhoffer, \& Turner, 2005). However, the question of whether free will actually exists or not is a long-standing philosophical debate (Dennett, 2015; Van Inwagen, 1983). Within the last decades, (cognitive) neuroscientists started entering the debate (cf. Crick, 1994; Harris, 2012; Wegner, 2002). One of the most well-known experiments on this topic was conducted by Libet, Gleason, Wright, and Pearl (1983). During this experiment, neural activity in the brain was measured with electroencephalography (EEG) before and after participants made spontaneous and voluntary finger movements. In addition, participants indicated the time when they perceived their first urge to initiate a movement. The researchers found an increase in neural activity several hundred milliseconds before participants reported being aware of an urge to initiate a movement. Although this and similar findings have been used 
to suggest that free will does not exist (Libet et al., 1983; Libet, Wright, \& Gleason, 1993), the link between such findings and free will is actually less clear (Saigle, Dubljević, \& Racine, 2018). Nevertheless, many media articles reported that Libet et al.'s experiments speak in favor of the nonexistence of free will despite acknowledging that several methodological limitations had been identified in the literature (Racine, Nguyen, Saigle, \& Dubljevic, 2017). Since anti free-will viewpoints became popular in the media, researchers started investigating whether it matters if people believe in free will by testing psychological and social consequences of free will beliefs (e.g., Baumeister, 2008; EwusiBoisvert \& Racine, 2018; Genschow, Rigoni, \& Brass, 2017; Rigoni \& Brass, 2014; Rigoni \& Brass, 2015; Schooler, Nadelhoffer, Nahmias, \& Vohs, 2014; Shariff et al., 2014; Vohs \& Schooler, 2008).

Such psychological research demonstrated that believing in free will has several downstream consequences. For instance, it has been found that people who believe in free will perform better in self-control tasks (Rigoni, Kühn, Gaudino, Sartori, \& Brass, 2012), but also in a variety of other contexts, such as in work (Stillman et al., 2010) and academic settings (Feldman, Chandrashekar, \& Wong, 2016). Moreover, free will beliefs predict higher job satisfaction (Feldman, Farh, \& Wong, 2018). When weakening individuals' belief in free will, researchers found increased antisocial behavior, such as cheating (Martin, Rigoni, \& Vohs, 2017; Vohs \& Schooler, 2008), racism (Zhao, Liu, Zhang, Shi, \& Huang, 2014), and aggressiveness towards others (Baumeister et al., 2009), as well as decreased prosocial attitudes expressed in altruistic (Baumeister et al., 2009) and cooperative behavior (Protzko, Ouimette, \& Schooler, 2015).

Neuroscience and cognitive research suggest that such behavioral changes stemming from reduced free will beliefs may be linked to a degradation of neural and cognitive mechanisms underlying intentional action preparation (Rigoni, Kühn, Sartori, \& 
Brass, 2011), deliberate motor inhibition (Lynn, Van Dessel, \& Brass, 2013; Rigoni et al., 2012), or the processing of performance errors (Rigoni, Pourtois, \& Brass, 2015; Rigoni, Wilquin, Brass, \& Burle, 2013).

Yet, an open and more basic question is whether and how belief in free will affects the perception of others' behavior. Perceiving and interpreting the behavior of others is one of the most critical tasks people face in everyday social life (e.g., Heider, 1958; Jones, 1979). People constantly judge and categorize others in an automatic fashion (e.g., Bruner, 1957; Fodor, 1983; Nisbett \& Wilson, 1977), and this largely determines how we eventually interact with them (Harris \& Garris, 2008; Kenny, 1994; Macrae \& Bodenhausen, 2000). Thereby, perceiving the intentionality of a certain behavior may shape the way individuals interact with each other (e.g., Genschow, Bardi, \& Brass, 2018; Genschow \& Brass, 2015). Indeed, perceiving the intentionality of others' behavior is one of the most fundamental tasks in our society as it is the basis for many important decisions. In the legal system, for example, punishment strongly depends on the degree to which a person acted intentionally. Likewise, in sports, disciplinary punishments by referees often depend on how intentional a player's behavior was. The most prominent example in this respect is probably handball in soccer, because punishment for such a misbehavior depends on whether the player intentionally touched the ball with the hand or arm (Federation Internationale de Football Association, 2015).

Taken together, past research has demonstrated that believing in free will increases perceived intentional control of one's own actions (Aarts \& van den Bos, 2011; Lynn et al., 2014; Rigoni et al., 2012). As people use their own representations to understand and predict other people's behavior (e.g., Gallese \& Goldman, 1998), it is reasonable to assume that the more individuals believe in free will, the more they perceive not only their own actions, but also others' actions as intentionally driven. First support for this reasoning 
comes from research showing that belief in free will decreases people's tolerance for unethical behavior (Clark et al., 2014; Shariff \& Vohs, 2014) and increases participants' tendency to punish (Shariff et al., 2014; Martin, Rigoni, \& Vohs, 2017; Genschow, Rigoni, \& Brass, 2017) or to reward others (Genschow, Rigoni, \& Brass, 2017). In the present article, we argue that such effects may stem from an increased perception of intentionality.

\section{Overview of Research}

In order to test the hypothesis that belief in free will is related to perceiving other people's behavior as intentionally driven, we conducted three studies. In Study 1a and 1b we measured participants' belief in free will, showed participants video clips of soccer players committing handball and asked them to indicate how intentional the players' action was. In Study 2 we tested whether belief in free will is not only related to perceived intentionality of concrete and real-live actions, but also applies to the perceived intentionality of moving abstract geometric shapes. All studies were conducted according to the ethical rules presented in the General Ethical Protocol of the Faculty of Psychology and Educational Sciences at Ghent University. At the beginning of each study, participants provided informed consent of the study and were informed that participation was voluntary and that all answers were processed and stored anonymously. The data of all studies and the German translation of the Free Will Inventory (FWI; Nadelhoffer, Shepard, Nahmias, Sripada, \& Ross, 2014) are made open accessible at the Open Science Framework (OSF; https://osf.io/q6bt2/).

\section{Study 1a}

\section{Method}

Participants. We recruited German speaking participants online via Facebook by advertising our study in groups that are interested in participating in psychological studies. A total of 108 participants $(38.9 \%$ female) with ages ranging from 14 to $90(M=29.86, S D$ 
$=12.35$ ) agreed to voluntarily participate in the study.

Procedure. Participants participated online in our study. They first saw 10 different video clips. In each video clip a soccer player committed handball within the penalty area. The video clips were taken from a video-based online training tool (Schweizer, Plessner, Kahlert, \& Brand, 2011) that is used for improving soccer referees' decisions. All handball actions committed within the videos had previously been pre-rated by a professional referee expert panel. In 5 videos, the soccer players intentionally touched the ball with their arm or hand. In the other five videos, the players accidentally touched the ball with their arm or hand. In order to prevent that participants might know the teams within the videos, we chose games that had taken place in lower German leagues. Moreover, we placed a black bar over the videos so participants could not see the current score, the elapsed time in the game and the name of the teams. Participants were allowed to watch each video multiple times. To measure perceived intentionality, participants indicated for each video their agreement on a 7-point rating scale $(1=$ strongly disagree; $4=$ neither; $7=$ strongly agree $)$ for the statement "The player touched the ball with his hand/arm intentionally". To prepare the data for analysis we computed three scores. First, we calculated an overall score of perceived intentionality by averaging the indicated intentionality of all videos. Second, we calculated a mean score of perceived intentionality for videos in which the players intentionally touched the ball with their arm/hand. Third, we computed a mean score of perceived intentionality for videos in which the players accidentally touched the ball with their arm/hand. After rating the videos, participants filled in the German version (see https://osf.io/q6bt2/) of the Free Will Inventory (FWI; Nadelhoffer, Shepard, Nahmias, Sripada, \& Ross, 2014) to assess participants' belief in free will. The FWI includes 15 items measuring the strength of belief in free will (Cronbach's $\alpha=.59$ ), determinism (Cronbach's $\alpha=.76)$ and dualism (Cronbach's $\alpha=.75)$ on 7-point rating scales. To 
compute an overall score of the scale we computed the mean of the free will, dualism and reversed determinism subscale. 
Table 1.

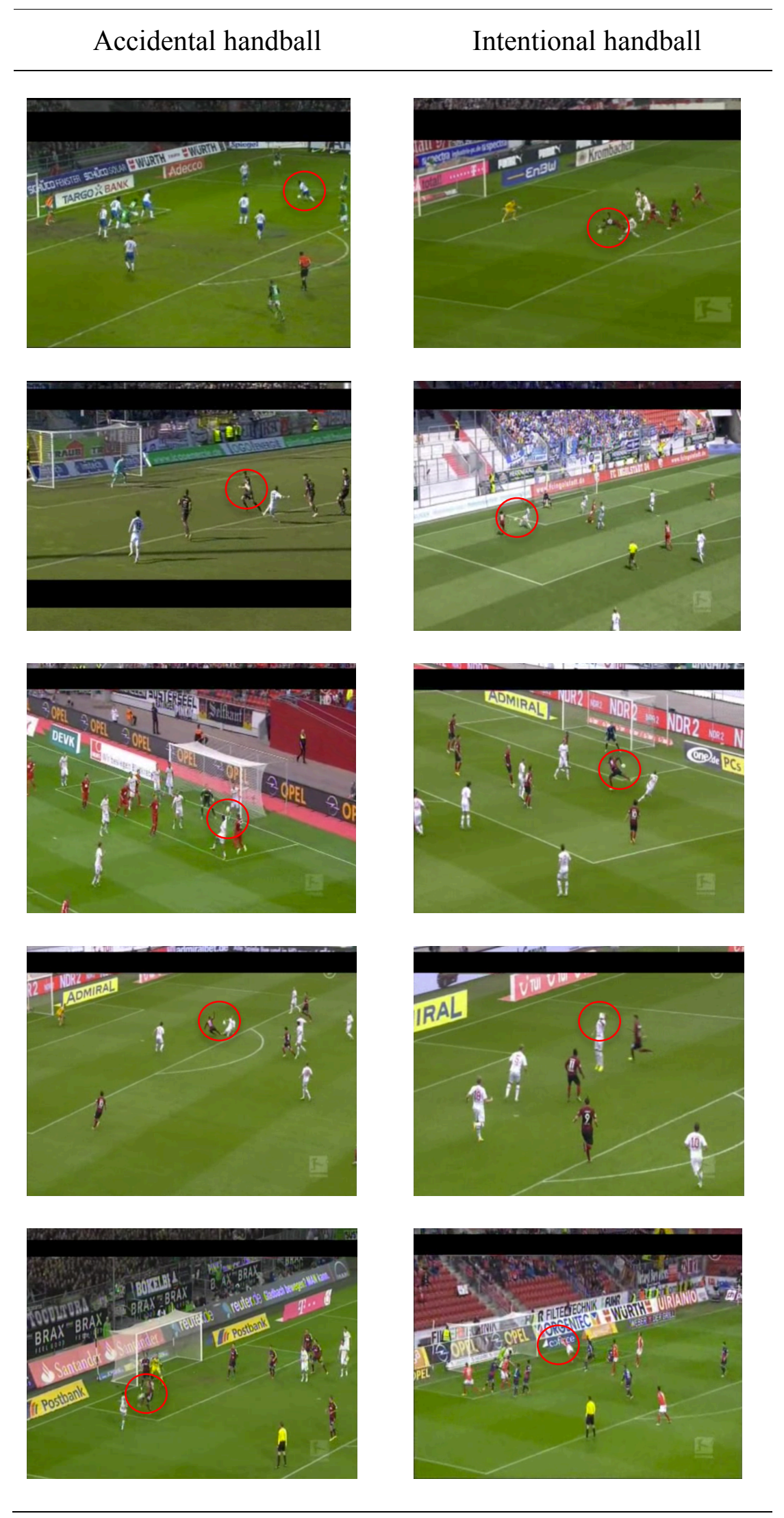

Table 1. Screenshots of all videos used in Study $1 \mathrm{a}$ and $1 \mathrm{~b}$ divided into handball committed accidentally versus intentionally. Red circles highlight the handball incident. Note, the red circles were not implemented in the actual study. 
At the end, participants indicated basic demographics and were debriefed (i.e., they read additional information about our general hypotheses).

\section{Results}

In order to test our hypothesis that belief in free will is positively correlated with perceived intentionality we ran multiple correlation analyses. First, we correlated the overall score of perceived intentionality with all FWI subscales (i.e., free will, dualism, and determinism) as well as the FWI overall score. The analysis indicated that the belief in free will subscale was positively correlated with the overall score of perceived intentionality, $r$ $=.23, p=.015, \mathrm{CI}[0.05,0.42]$. Further correlational analyses indicated that neither dualism $(r=.14, p=.145)$, nor determinism $(r=.16, p=.109)$, nor the FWI overall score $(r=.11, p=.281)$ was correlated with the overall score of perceived intentionality.

In an additional analysis, we ran a multiple regression analysis with all the FWI subscales as predictors and the overall score of perceived intentionality as the dependent variable. When entering the dualism and determinism subscale into the regression equation, belief in free will remained significant in predicting perceived intentionality, $\beta=.20, t=$ $2.01, p=.047$, CI $[0.003,0.38]$.

In a final series of analyses we tested whether it matters if soccer players objectively committed handball intentionally or not. First, we tested whether participants perceived handball as more intentional within videos in which the players actually intentionally touched the ball with their arm or hand. A t-test for dependent samples indicated that participants indeed perceived handball as more intentional when players intentionally committed handball $(M=4.16, S D=1.06)$ as compared to when players accidentally committed handball $(M=2.79, S D=1.32), t(107)=10.56, p<.001$, CI $[1.11,1.62], d z=1.02$. Second, we tested whether belief in free will correlates with the two different forms of committing handball (i.e., intentional vs. accidental). Interestingly, 
belief in free will subscale seems to correlate with perceived intentionality irrespective of whether the player actually committed handball intentionally, $r=.21, p=.027$, CI [0.03, 0.40], or accidentally, $r=.18, p=.062$, CI [-0.01, 0.37].

\section{Study 1b}

Study la gives first support for our hypothesis that belief in free will is positively associated with perceiving intentionality in other persons' behavior. However, one may argue that with 108 participants the study was slightly underpowered. Thus, in order to replicate the results obtained in Study la with a higher powered sample, we conducted a preregistered replication (study plan available at https://aspredicted.org/3j95s.pdf).

\section{Method}

Participants and Procedure. Participants were recruited via mailing lists of the University of Cologne (Germany). As compensation for their participation, subjects could participate in a lottery to win a 10 EURO Amazon voucher. Based on recommendations for the assessment of stable correlations put forward by Schönbrodt and Perugini (2013), we collected data from 250 participants (62\% female). Ages ranged from 18 to 65 ( $M=26.86$, $S D=6.33)$

The procedure of the study was exactly the same as in Study 1a. In line with Study 1a, we presented participants with 10 videos of soccer players committing handball and assessed participants' belief in free will with the German translation (see https://osf.io/q6bt2/) of the FWI (Nadelhoffer et al., 2014). Cronbach's Alpha was $\alpha=.69$ for the free will subscale, $\alpha=.72$ for the determinism subscale and $\alpha=.74$ for the dualism subscale.

\section{Results}

Preregistered analyses. The results of Study $1 \mathrm{~b}$ replicate the results obtained in Study 1a (see Figure 1). That is, the belief in free will subscale was positively correlated 
with the overall score of perceived intentionality, $r=.21, p=.001$, CI $[0.09,0.33]$. The overall score of the FWI did not correlate significantly with the overall score of perceived intentionality, $r=.10, p=.134$.

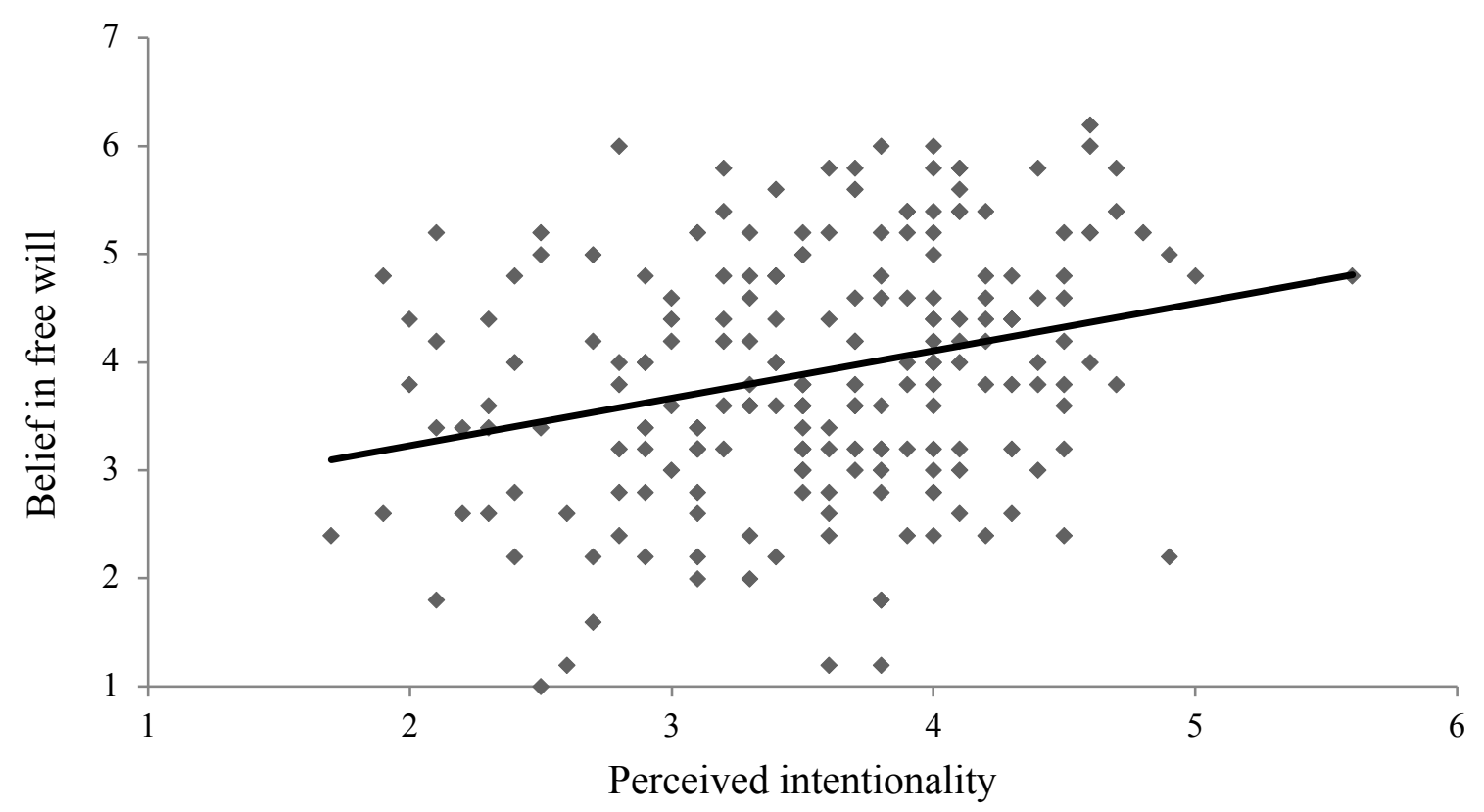

Figure 1. Plotted correlation between belief in free will and perceived intentionality in soccer players committing handball in Study $1 b$.

Additional explorative analyses. In additional correlational analyses we found that determinism correlated with the overall score of perceived intentionality as well $r=.18, p=$ .005, CI $[0.05,0.30]$. Dualism was marginally significantly correlated with the overall score of perceived intentionality, $r=.12, p=.065, \mathrm{CI}[-0.01,0.24]$. In order to test whether belief in free will explains variance separately from the other subscales, we ran a multiple regression analysis with all the FWI subscales as predictors and the overall score of perceived intentionality as the dependent variable. When entering the dualism and determinism subscale into the regression equation, the belief in free will subscale remained significant in predicting perceived intentionality, $\beta=.17, t=2.66, p=.008$, CI [0.03, $0.19]$.

In a final series of analyses we tested whether belief in free will is related to 
perceived intentionality irrespective of whether the player actually touched the ball intentionally or accidentally. A first analysis indicated that participants perceived handball as more intentional when players intentionally committed handball $(M=3.98, S D=0.79)$ as compared to when players accidentally committed handball $(M=3.11, S D=0.98)$, $t(249)=12.26, p<.001, \mathrm{CI}[0.72,1.00], d z=.78$. A second analysis indicated that the belief in free will subscale correlated with perceived intentionality irrespective of whether the players committed handball intentionally, $r=.14, p=.023$, CI [0.02, 0.27], or accidentally, $r=.18, p=.004, \mathrm{CI}[0.06,0.31]$

\section{Discussion}

In Study 1a and 1b, we presented participants with video clips of soccer players committing handball and found first support for our general hypothesis: The more participants believed in free will, the more intent they perceived behind other people's behavior $^{1}$. Despite these results, there are a few issues that need to be addressed in order to draw strong conclusions. First, in Study $1 \mathrm{a}$ and $1 \mathrm{~b}$ we assessed perceived intentionality by asking whether participants perceived the behavior as intentionally driven with one item only. Thus, it might be that individuals who believe in free will have the general tendency to agree with everything, which could explain the correlation with perceived intentionality. Second, the question arises as to whether our effects are specific to the domain of soccer, or whether they can be generalized to other behaviors as well.

Third, in our first studies participants perceived behavior as intentionally driven even when the players objectively touched the ball with their hand or arm accidentally.

\footnotetext{
${ }^{1}$ In an additional exploratory analysis we pooled the data from Study 1a and Study $1 \mathrm{~b}$ and tested whether there is a gender difference in the correlation between perceived intentionality and belief in free will. This analysis indicates that the correlation between the belief in free will subscale and the overall score of perceived intentionality was similarly strong in female participants $\left(r_{\text {female }}=.24, p=.001, \mathrm{CI}[0.11,0.41]\right)$ as compared to male participants $\left(r_{\text {male }}=.19, p=.019\right.$, CI $\left.[0.03,0.32]\right)$. A comparison between the two correlation coefficients revealed that the two coefficients are not significantly different from each other, $Z=$ $0.49, p=.31$.
} 
This may suggest that individuals who believe in free will perceive any kind of behavior as intentional. However, as the behavior in the soccer videos was embedded in a very rich social context, many secondary factors could have influenced participants' perception. For example, the players from the other team usually protested and claimed a penalty even if handball was conducted accidentally. Moreover, the reaction of the fans or the reaction of the player committing handball may have influenced the perception as well. Based on such potential confounding variables, researchers often assess perceived intentionality by using stimuli that eliminate any low-level, animate-specific sensory cues. For example, researchers often use abstract stimuli such as animations of simple geometric shapes that avoid any veridical cues such as faces, eyes, or articulated joints (e.g., Castelli, Happé, Frith, \& Frith, 2000; Martin \& Weisberg, 2003).

Thus, to rigorously test whether individuals who believe in free will infer intentions even in very abstract shapes and to control for possible low-level confounding variables, we conducted Study 2. Moreover, we assessed perceived intentionality with differently poled items to rule out that our effects are driven by participants' general tendency to agree with everything.

\section{Study 2}

In order to test our predictions we conducted a high-powered and preregistered study (study plan available at https://aspredicted.org/b8sx7.pdf).

\section{Method}

Participants. Participants were invited online via Amazon's Mechanical Turk. In line with Study $1 \mathrm{~b}$ and the recommendations put forward by Schönbrodt and Perugini (2013), we collected data from 250 participants (51,2 \% female). Ages ranged from 19 to $76(M=35.01, S D=11.21)$

Procedure. In order to measure participants' perceived intentionality we presented 
them with four video clips of moving geometrical shapes that were borrowed from Castelli et al. (2000). The characters in the videos were two triangles whose movement patterns evoke simple actions. Specifically, we selected videos in which abstract intentions could be inferred (i.e., dancing, chasing, fighting, leading). After watching each of the videos, participants indicated their agreement with the following two statements "The triangles behaved intentionally" and "The triangles moved randomly" on 7-point scales ranging from 1 (applies not at all) to 7 (applies very much). In order to calculate a mean score of perceived intentionality, we averaged the rating of the first statement with the reversed coded rating of the second statement.

After rating the videos, participants filled in the Free Will Inventory (FWI; Nadelhoffer et al., 2014) to assess participants' belief in free will. Cronbach's Alpha was $\alpha$ $=.84$ for the free will subscale, $\alpha=.85$ for the determinism subscale and $\alpha=.87$ for the dualism subscale. To achieve an overall score of the scale we computed the mean of the free will, dualism and reversed determinism subscale. 
Table 2.

Behavior

Frames

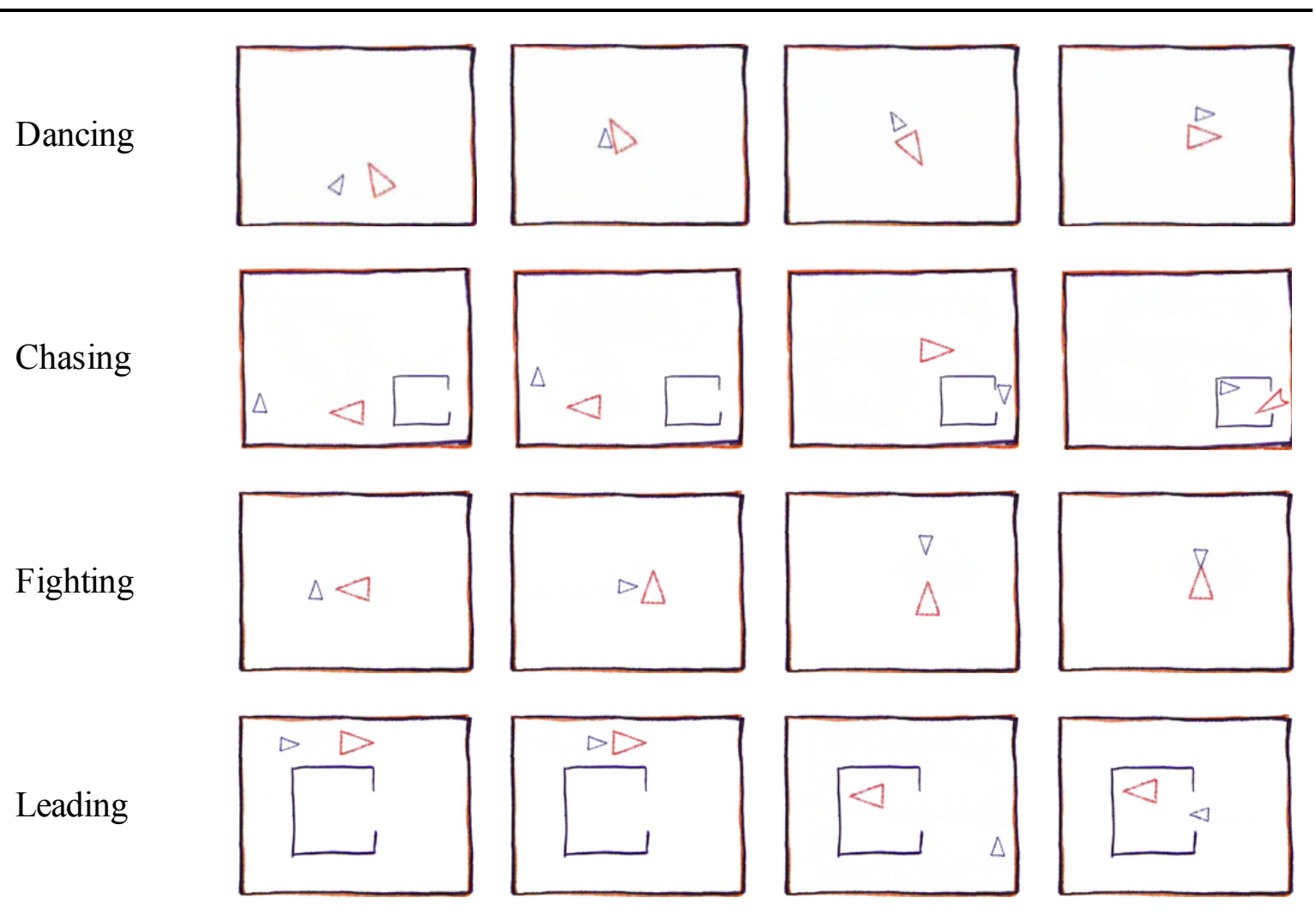

Table 2. Screenshots of the videos used in Study 2.

\section{Results}

Preregistered analyses. To test our hypothesis that belief in free will is positively correlated with perceived intentionality of moving geometric shapes, we ran a correlational analysis. As hypothesized, the belief in free will subscale correlated positively with perceived intentionality, $r=.15, p=.021$, CI [0.22, 0.27]. Moreover, the overall score of the FWI correlated significantly with perceived intentionality as well, $r=.20, p=.002$, CI $[0.07,0.32]$

Additional explorative analyses. Further analyses showed that determinism correlated negatively with perceived intentionality, $r=-.19, p=.003$, CI [-0.31, -0.06$]$, and dualism did not correlate with perceived intentionality, $r=.03, p=.592$. 
In an additional analysis, we computed a multiple regression analysis with all the FWI subscales as predictors and perceived intentionality as the dependent variable. In line with Studies 1a and 1b, the belief in free will subscale remained significant in predicting perceived intentionality when entering the dualism and determinism subscale into the regression equation, $\beta=.18, t=2.59, p=.010$, CI [0.04, 0.32].

\section{General Discussion}

In three studies, we tested the hypothesis that individuals who believe in free will perceive more intent behind other persons' behavior than individuals who believe less in free will. In Study 1a and 1b we presented participants with videos of soccer players committing handball. Participants perceived the football players' actions as more intentional the more they believed in free will. Interestingly, this effect even persisted when handball was committed accidentally and not intentionally. In line with this finding, Study 2 demonstrated that participants who believe in free will even perceive more intentions in abstract geometrical shapes. This indicates that belief in free will is linked to a very basic and fundamental process underlying human social perception. Thus, we assume that even individuals believing in free will who are not familiar with soccer would perceive more intentions in soccer players committing handball. Future research may aim at testing this assumption more directly.

In philosophy, there has been a debate surrounding the question of whether disbelief in free will might have detrimental (Smilansky, 2000) or beneficial (Pereboom, 2006) consequences for society. Our data provide empirical evidence that such debates are not merely theoretical but have highly relevant real-life implications. Moreover, our results provide a new perspective on past research on belief in free will. Previous research (e.g., Rigoni et al., 2011; 2012; 2013; 2015) has indicated that belief in free will increases the perceived intentionality of one's own actions. In the present research, we demonstrated that 
belief in free will increases perceived intentionality of others' actions as well.

Moreover, our research might have implications for research on punishment. That is, with a stronger belief in free will, people may punish other persons' misbehavior more strongly, because they perceive behavior as more intentionally driven. Indeed, past research has shown that belief in free will decreases people's tolerance for unethical behavior (Clark et al., 2014; Shariff \& Vohs, 2014) and increases participants' tendency to punish others (Shariff et al., 2014; Martin, Rigoni, \& Vohs, 2017; Genschow, Rigoni, \& Brass, 2017). Our research offers a potential explanation for these findings on a process level by suggesting that free will beliefs increase perceived intentionality. Going one step further, we would like to argue that perceiving others' behavior as more intentionally driven should lead individuals to reward positive behavior more strongly. First support for this reasoning comes from recent research showing that the more people believe in free will, the more they reward positive behavior (Genschow, Rigoni, \& Brass, 2017). The present findings suggest that this effect might be due to an increase in perceived intentionality.

In addition, our results contribute to research on the fundamental attribution error (Gilbert \& Malone, 1995; Heider, 1958; Ross, 1977) and the actor-observer bias (Jones \& Nisbett, 1971; Nisbett, Caputo, Legant, \& Marecek, 1973). Such research indicates that individuals have the tendency to perceive other people's behavior as more strongly driven by internal forces (e.g., personality) and as less strongly driven by external factors (e.g., situation). Interestingly, we recently found that belief in free will increases the fundamental attribution error (Genschow et al., 2017) — that is, the more participants believed in free will, the more they perceived other people's behavior as driven by internal, as compared to external forces. The present research offers a potential explanation for this finding: The more individuals believe in free will, the more intentions they perceive in others' actions. Perceived intentions, in turn, may increase attributions to internal factors and decrease 
attributions to external factors.

Besides theoretical implications, our findings have important societal consequences. For instance, the results might be particularly relevant to court cases. Because in the legal system punishment strongly depends on the degree to which a person acted intentionally, our results suggest that free will beliefs may move judges and jurors toward harsher punishments. It is crucial to note that this logic is not restricted to court cases, but can be applied to any situation in which individuals judge others. For example, in educational settings, belief in free will should influence how intentional a behavior is perceived to be, which should lead teachers or parents to punish and reward children more strongly. Likewise, in sports, referees who believe in free will should perceive misbehavior as more intentionally driven, which may result in harsher penalty decisions.

It is important to note that the findings reported here do not speak to the larger discussion on the existence of free will. In fact, it might well be that free will is nothing more than an illusion, but nevertheless offers some functionality. In contrast, it also seems possible to integrate a genuine sense of free will into scientific accounts of human behavior (e.g., Baumeister, 2008; Dennett, 2004; Kane, 1998; Shariff, Schooler, \& Vohs, 2008). Although the question of whether free will exists or not remains open, our results demonstrate that the strength with which individuals believe in free will is of crucial relevance, because it influences how we perceive our social environment. 


\section{References}

Association, F. I. d. F. (2015). Laws of the Game 2015/2016. Zürich, Switzerland:

Federation Internationale de Football Association.

Baumeister, R. F. (2008). Free will in scientific psychology. Perspectives on Psychological Science, 3, 14-19.

Baumeister, R. F., Masicampo, E., \& DeWall, C. N. (2009). Prosocial benefits of feeling free: Disbelief in free will increases aggression and reduces helpfulness. Personality and Social Psychology Bulletin, 35, 260-268.

Bruner, J. S. (1957). On perceptual readiness. Psychological Review, 64, 123-152.

Castelli, F., Happé, F., Frith, U., \& Frith, C. (2000). Movement and mind: a functional imaging study of perception and interpretation of complex intentional movement patterns. Neuroimage, 12, 314-325.

Clark, C. J., Luguri, J. B., Ditto, P. H., Knobe, J., Shariff, A. F., \& Baumeister, R. F. (2014). Free to punish: A motivated account of free will belief. Journal of Personality and Social Psychology, 106, 501-513.

Crick, F. (1994). The Astonishing Hypothesis: The Science Search for the Soul. New York: Touchstone.

Dennett, D. C. (2004). Freedom evolves. London: Allen Lane.

Dennett, D. C. (2015). Elbow room: The varieties of free will worth wanting: MIT Press.

Ewusi-Boisvert, E., \& Racine, E. (2018). A critical review of methodologies and results in recent research on belief in free will. Neuroethics, 1-14.

Feldman, G., Chandrashekar, S. P., \& Wong, K. F. E. (2016). The freedom to excel: Belief in free will predicts better academic performance. Personality and Individual Differences, 90, 377-383. 
Feldman, G., Farh, J.-L., \& Wong, K. F. E. (2018). Agency beliefs over time and across cultures: Free will beliefs predict higher job satisfaction. Personality and Social Psychology Bulletin, 44, 304-317.

Fodor, J. A. (1983). The modularity of mind: An essay on faculty psychology. Palatino: MIT press.

Genschow, O., Bardi, L., \& Brass, M. (2018). Anticipating actions and corticospinal excitability: a preregistered motor TMS experiment. Cortex, 81-92. doi: 10.1016/j.cortex.2018.04.014

Genschow, O., \& Brass, M. (2015). The predictive chameleon: Evidence for anticipated action. Journal of Experimental Psychology: Human Perception and Performance, $41,265-268$.

Genschow, O., Rigoni, D., \& Brass, M. (2017). Belief in free will affects causal attributions when judging others' behavior. Proceedings of the National Academy of Sciences, 114, 10071-10076.

Gilbert, D. T., \& Malone, P. S. (1995). The correspondence bias. Psychological Bulletin, 117, 21-38.

Harris, M. J., \& Garris, C. P. (2008). You never get a second chance to make a first impression: Behavioral consequences of first impressions. In N. Ambady \& J. J. Skowronski (Eds.), First impressions (pp. 147-168). New York: Guilford Publications.

Harris, S. (2012). Free will. New York: Simon and Schuster.

Heider, F. (1958). The psychology of interpersonal relations. New York: Wiley.

Jones, E., \& Nisbett, R. E. (1971). The actor and the observer: Divergent perceptions of the causes of behavior. New York: General Learning Press. 
Jones, E. E. (1979). The rocky road from acts to dispositions. American Psychologist, 34, 107-117.

Kane, R. (1998). The significance of free will. Oxford, England: Oxford University Press.

Kenny, D. A. (1994). Interpersonal perception: A social relations analysis. New York: Guilford Press.

Libet, B., Gleason, C. A., Wright, E. W., \& Pearl, D. K. (1983). Time of conscious intention to act in relation to onset of cerebral activity (readiness-potential) the unconscious initiation of a freely voluntary act. Brain, 106, 623-642.

Libet, B., Wright, E. W., \& Gleason, C. A. (1993). Readiness-potentials preceding unrestricted'spontaneous' vs. pre-planned voluntary acts Neurophysiology of Consciousness (pp. 229-242): Springer.

Lynn, M., Van Dessel, P., \& Brass, M. (2013). The influence of high-level beliefs on selfregulatory engagement: evidence from thermal pain stimulation. Frontiers in Psychology, 4. doi: 10.3389/fpsyg.2013.00614

Macrae, C. N., \& Bodenhausen, G. V. (2000). Social cognition: Thinking categorically about others. Annual Review of Psychology, 51, 93-120.

Martin, A., \& Weisberg, J. (2003). Neural foundations for understanding social and mechanical concepts. Cognitive Neuropsychology, 20, 575-587.

Martin, N. D., Rigoni, D., \& Vohs, K. D. (2017). Free Will Beliefs Predict Attitudes toward Unethical Behavior and Criminal Punishment: A Global Analysis. Proceedings of the National Academy of Sciences, 114, 7325-7330.

Nadelhoffer, T., Shepard, J., Nahmias, E., Sripada, C., \& Ross, L. T. (2014). The free will inventory: Measuring beliefs about agency and responsibility. Consciousness and cognition, 25, 27-41. 
Nahmias, E., Morris, S., Nadelhoffer, T., \& Turner, J. (2005). Surveying freedom: Folk intuitions about free will and moral responsibility. Philosophical Psychology, 18, $561-584$

Nisbett, R. E., Caputo, C., Legant, P., \& Marecek, J. (1973). Behavior as seen by the actor and as seen by the observer. Journal of Personality and Social Psychology, 27, 154.

Nisbett, R. E., \& Wilson, T. D. (1977). Telling more than we can know: Verbal reports on mental processes. Psychological Review, 84, 231-259.

Pereboom, D. (2006). Living without free will. New York: Cambridge University Press.

Protzko, J., Ouimette, B., \& Schooler, J. (2015). Believing There Is No Free Will Corrupts Intuitive Cooperation. Available at SSRN 2490855.

Racine, E., Nguyen, V., Saigle, V., \& Dubljevic, V. (2017). Media portrayal of a landmark neuroscience experiment on free will. Science and Engineering Ethics, 23, 9891007.

Rigoni, D., \& Brass, M. (2014). From intentions to neurons: social and neural consequences of disbelieving in free will. Topoi, 33, 5-12.

Rigoni, D., \& Brass, M. (2015). Belief in free will and trust. Unpublished raw data.

Rigoni, D., Kühn, S., Gaudino, G., Sartori, G., \& Brass, M. (2012). Reducing self-control by weakening belief in free will. Consciousness and cognition, 21, 1482-1490.

Rigoni, D., Kühn, S., Sartori, G., \& Brass, M. (2011). Inducing disbelief in free will alters brain correlates of preconscious motor preparation the brain minds whether we believe in free will or not. Psychological Science, 22, 613-618.

Rigoni, D., Pourtois, G., \& Brass, M. (2015). 'Why should I care?'Challenging free will attenuates neural reaction to errors. Social Cognitive and Affective Neuroscience, $10,262-268$. 
Rigoni, D., Wilquin, H., Brass, M., \& Burle, B. (2013). When errors do not matter: Weakening belief in intentional control impairs cognitive reaction to errors. Cognition, 127, 264-269.

Ross, L. (1977). The intuitive psychologist and his shortcomings: Distortions in the attribution process. Advances in Experimental Social Psychology, 10, 173-220.

Saigle, V., Dubljević, V., \& Racine, E. (2018). The impact of a landmark neuroscience study on free will: A qualitative analysis of articles using Libet and colleagues' methods. AJOB Neuroscience, 9, 29-41.

Schönbrodt, F. D., \& Perugini, M. (2013). At what sample size do correlations stabilize? Journal of Research in Personality, 47, 609-612.

Schooler, J., Nadelhoffer, T., Nahmias, E., \& Vohs, K. D. (2014). Measuring and manipulating beliefs and behaviors associated with free will. Surrounding free will: Philosophy, psychology, neuroscience, 72.

Schweizer, G., Plessner, H., Kahlert, D., \& Brand, R. (2011). A video-based training method for improving soccer referees' intuitive decision-making skills. Journal of Applied Sport Psychology, 23, 429-442.

Shariff, A. F., Greene, J. D., Karremans, J. C., Luguri, J. B., Clark, C. J., Schooler, J. W., . . . Vohs, K. D. (2014). Free will and punishment: A mechanistic view of human nature reduces retribution. Psychological Science, 25, 1563-1570.

Shariff, A. F., Schooler, J., \& Vohs, K. D. (2008). The Hazards ofClaiming to Have Solved the Hard Problem of Free Will. In J. C. Baer, J. C. Kaufmann \& R. F. Baumeister (Eds.), Are we free? Psychology and free will (pp. 181-204). Oxford: Oxford University Press.

Shariff, A. F., \& Vohs, K. D. (2014). The World Without Free Will. Scientific American, $310,76-79$. 
Smilansky, S. (2000). Free will and illusion. Oxford, New York: Oxford University Press

Stillman, T. F., Baumeister, R. F., Vohs, K. D., Lambert, N. M., Fincham, F. D., \& Brewer, L. E. (2010). Personal philosophy and personnel achievement: Belief in free will predicts better job performance. Social Psychological and Personality Science, 1, 43-50.

Van Inwagen, P. (1983). An essay on free will. London: MIT Press.

Vohs, K. D., \& Schooler, J. W. (2008). The value of believing in free will encouraging a belief in determinism increases cheating. Psychological Science, 19, 49-54.

Wegner, D. (2002). The illusion of free will: Cambridge, MA: MIT Press.

Zhao, X., Liu, L., Zhang, X.-x., Shi, J.-x., \& Huang, Z.-w. (2014). The effect of belief in free will on prejudice. PloS one, 9, e91572. 